\title{
TEM-ANALYSIS OF INCLUSIONS IN DIAMONDS FROM THE LOWER MANTLE AND TRANSITION ZONE (KANKAN DISTRICT, GUINEA)
}

\author{
Frank E. Brenker ${ }^{1}$, Thomas Stachel ${ }^{2}$ and Jeff W. Harris ${ }^{3}$ \\ ${ }^{1}$ University of Cologne, Germany; ${ }^{2}$ University of Alberta, Canada; ${ }^{3}$ University of Glasgow, Scotland, UK
}

\section{INTRODUCTION}

Inclusions in diamonds enable us to sample deep regions of our Earth's mantle. Recent work on inclusions from the Kankan district in Guinea [Brenker et al., 2002; Stachel et al., 2000a, 2000b] shows that these diamonds originate from depths down to the transition zone and the lower mantle. Diamonds not only form chemically inert containers, but also they protect their inclusions from deformation during later exhumation. Thus, these inclusions provide the unique opportunity to study directly the mechanisms of deformation occurring in the deep mantle.

A further task of our studies is to characterize features related to phase transitions, like antiphase domains, exsolution or twinning and to search for submicroscopic fluid inclusions or hydrous phases in order to test the hypothesis of an "ocean" in the transition zone.

\section{RESULTS}

\section{LOWER MANTLE MINERALS}

The lower mantle is a mixture of $\mathrm{Mg}$-silicate perovskite, ferropericlase and $\mathrm{Ca}$-silicate perovskite. So far, silicate perovskites have not been observed in their original crystallographic structure in samples from the transition zone and the lower mantle so far. Thus, ferropericlase which does not go through retrograde phase transformations is the only carrier of direct information on the rheology of the lower mantle.

\section{Ferropericlase}

Two ferropericlase inclusions were investigated. For both of them, a high dislocation density between $1 \times 10^{8}$ and $2 \times 10^{9} \mathrm{~cm}^{-2}$ was found. The relation of dislocations in respect to exsolved magnesioferrite (Figure 1) can be used to distinguish between dislocations which already exist during exsolution and those which were formed or which were mobile after exsolution took place. The magnesioferrite exsolution is along dislocations, which are arranged in subgrain boundaries (Figure 1). Thus this deformation and annealing process took place before the exsolution. The exact condition under which this exsolution occurred cannot be estimate. It is not possible to decide if the deformation of ferropericlase took place before or after inclusions of the grain into the diamond container. In the case of ferropericlase, differential expansion rates between inclusion and diamond host will produce enough stress in the inclusion. A second type of dislocation was mobile after the exsolution process and trapped at magnesioferrite crystals (Figure 2). The burgers vector both types of dislocations was determined to $b e b=\langle 110\rangle$ which are the most common vector of this structure and is also found experimentally

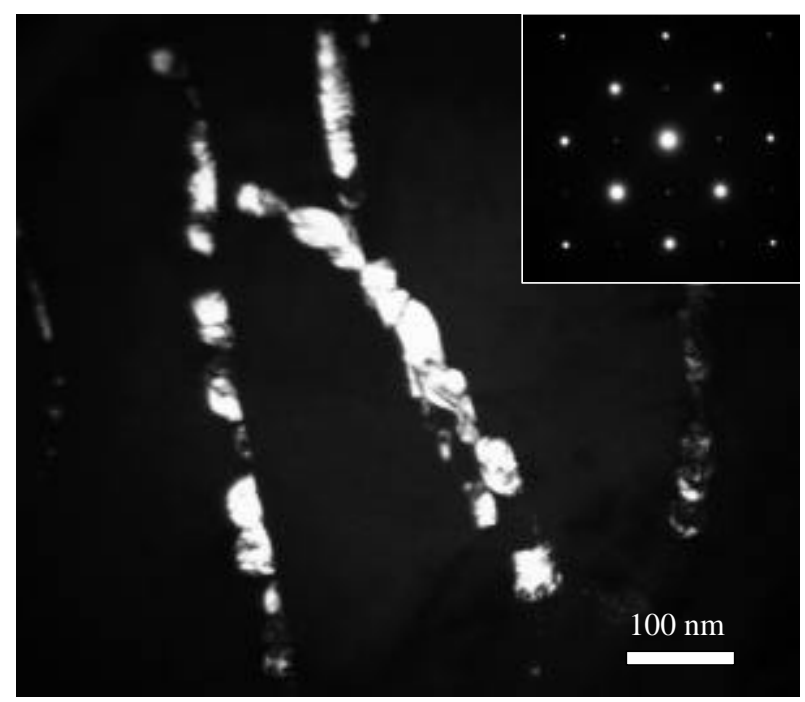

Figure 1: Dark field TEM micrograph with magnesioferrite in contrast. Upper right:SAED pattern of magnesioferrite exsolution in ferro-periclase intergrowth $\left([100]_{\mathrm{MgO}}\right.$ parallel $[100]_{\text {magnesioferrit }}$. 


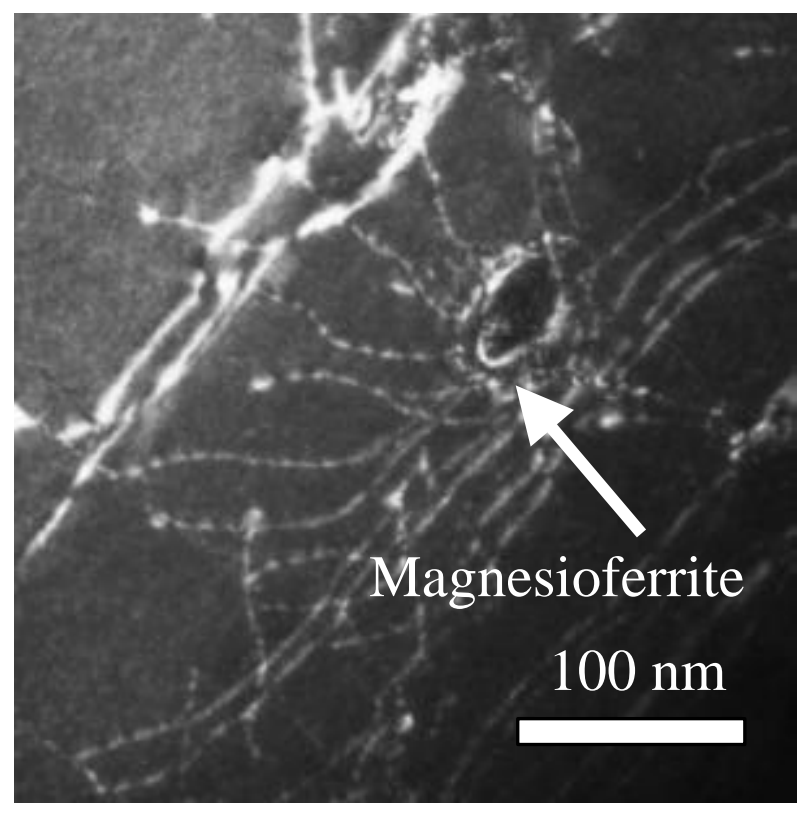

Figure 2: TEM "weak beam" dark field micrograph showing the pinning of dislocations at the exsolved magnesioferrite indicating deformation after the exsolution process.

\section{TRANSITION ZONE AND ASTHENOSPHERIC INCLUSIONS}

\section{Olivine}

Investigations on olivine were performed on inclusions which originated in the lower part of the upper mantle (Figure 3A-C) and on olivine which formed as a consequence of retrograde phase transformations from primary wadsleyite or ringwoodite (Figure 3D). In olivine inclusions from the upper mantle we found high dislocation densities (between $1 \times 10^{7}$ and $1 \times 10^{8} \mathrm{~cm}^{-2}$ ) as well as subgrain boundaries and dislocation loops. Burgers vector determinations yield an unusual high amount of $b=[001]$ dislocations. Normally, olivine from the upper mantle should show a predominance of $\mathrm{b}=[100]$ dislocations and these are observed in olivines from xenolith samples [e.g. Gueguen, Y, 1977]. However, $b=[001]$ dislocations, as found in the olivine inclusions, are usually favored during deformation at high stress, but low temperature [e.g. Langenhorst et al., 2002]. Mg-Al-chromite exsolution is observed very frequently which are formed during transformation of $\alpha$-olivine from its higher pressure polymorph wadsleyite or ringwoodite. The exsolution is always accompanied by dislocations. Dislocation densities are similar to upper mantle olivine inclusions studied in this work. A detailed burgers vector determination is in progress.
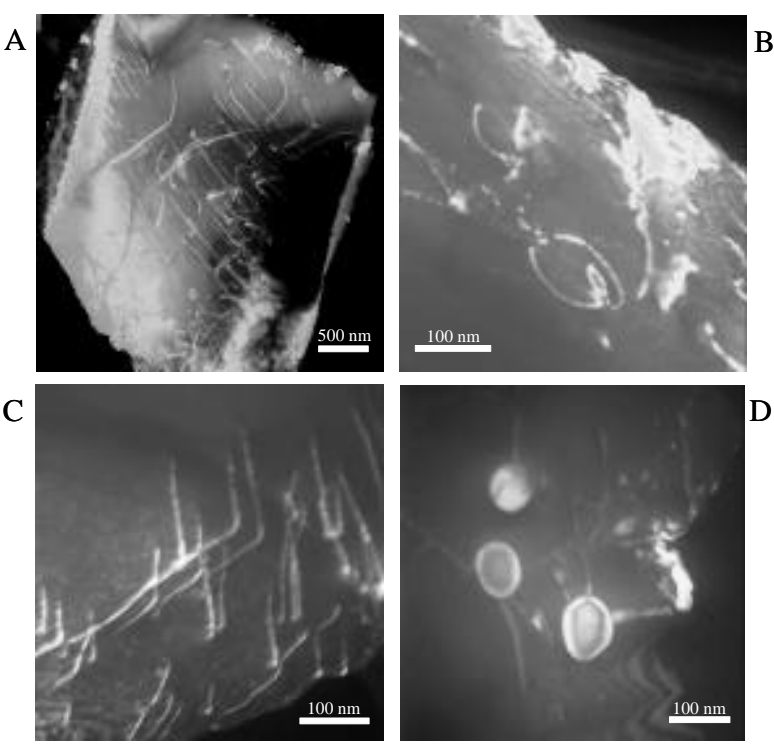

Figure 3: TEM "weak beam" dark field micrograph (A-C). (A) A crushed fragment of an olivine inclusion shows a high density of long, straight $b=[001]$ dislocations. (B) Dislocation loop in olivine having $b=[001]$. (C) Splitting into dislocation dipoles and probably partials. (D) Spinel exsolution in olivine transformed from its high pressure polymorph wadsleyite or ringwoodite

\section{Majoritic garnet}

Two majoritic garnets were prepared for TEM investigation. All studied fragments are free of dislocations and other submicroscopic features. Thus, garnet seems to be annealed completely during ascent of the sample in a hot kimberlite magma, or initially, never contain dislocations.

\section{Clinopyroxene}

Finally, clinopyroxene inclusions coexisting with majoritic garnet or resulting from retrograde phase transformations and reactions involving lower mantle perovskites were studied. Our TEM-data show that clinopyroxenes reacted from a former two phase inclusion of $\mathrm{Ca}$-silicate and $\mathrm{Mg}$-silicate perovskite [Brenker et al., 2002] show an unusually high amount of deformation twinning parallel (100) (Figure 4). Deformation twinning in clinopyroxene is well known from shocked meteorites and experiments involving high strain rates. Obviously, the large volume increase associated with the reaction $\mathrm{CaSi}-\mathrm{Pvk}+\mathrm{MgSi}-\mathrm{Pvk}=$ diopside occurring inside the diamond is quite capable to produce high stresses for the inclusion assemblage and thus is probably responsible for the observed microtwinning. A lower degree of twinning is observed in clinopyroxenes coexisting with majoritic garnets. For 
the dislocations a burgers vector $b=1 / 2<110\rangle$ was determined.

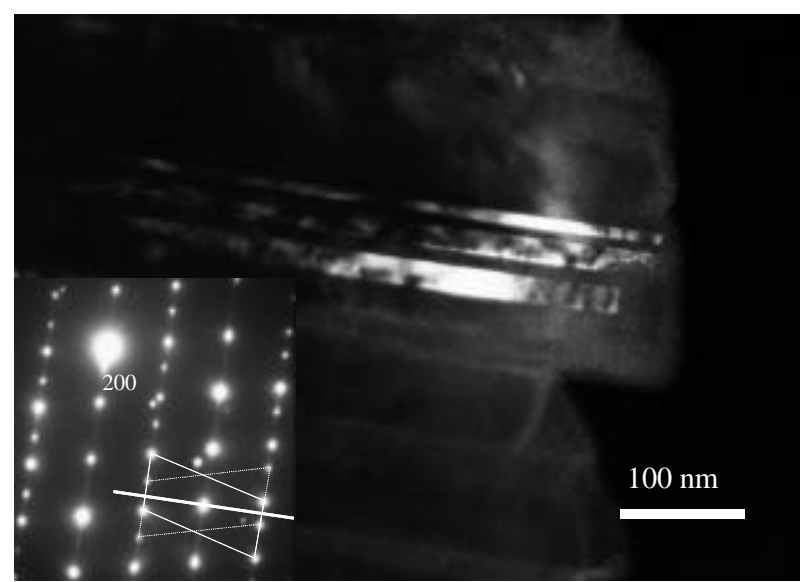

Figure 4: nm-scale deformation twinning parallel (100) in clinopyroxene transformed from lower mantle silicateperovskite

Several submicroscopic inclusions were found in clinopyroxene. Larger areas of $\mathrm{Al}$ and Si-rich amorphous materials were detected.

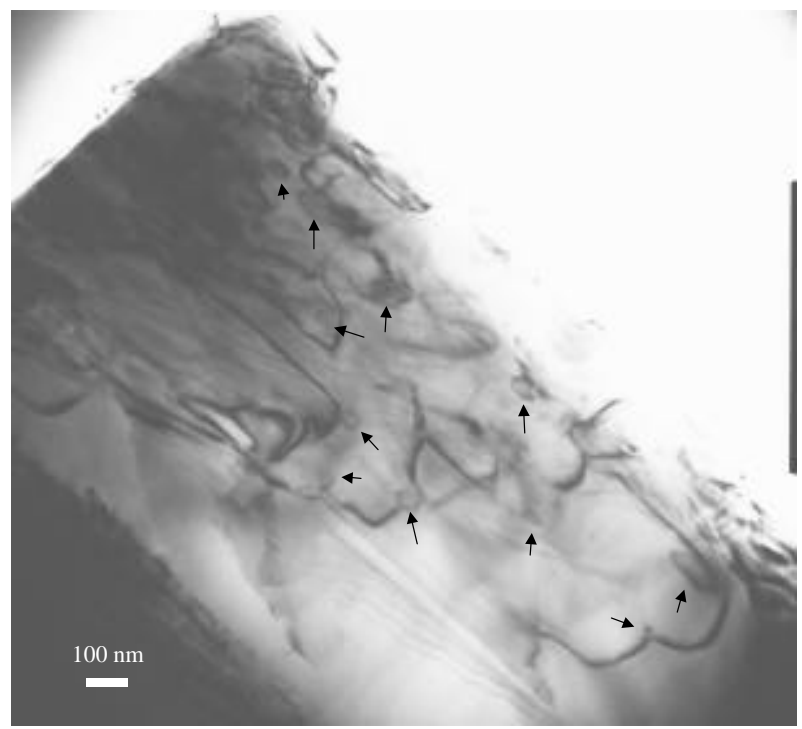

Figure 5: Fluid-Bubble in cpx from the transition zone

In some rare cases we found frequent $10-50 \mathrm{~nm}$ sized fluid inclusions (Figure 5). In a few cases, careful energy disper-sive $\mathrm{x}$-ray measurements yield a slight enrichment of $\mathrm{K}$ relative to the pyroxene background. The apparent ab-sence of other components during EDS analysis suggests a $\mathrm{C}-\mathrm{H}, \quad \mathrm{C}-\mathrm{O}$ or $\mathrm{C}-\mathrm{H}-\mathrm{O}$ rich composition of the fluid.

\section{CONCLUSION}

Most deformation features found in the inclusions point towards a high stress environment. Most likely these stresses are due to volume increases during retrograde phase transformations or differential expansion rates between inclusion and diamond host during ascent. Whether dislocations in ferropericlase which predates exsolution of magnesioferrite can be related directly to deformation and annealing processes in the lower mantle or simply reflects early stages of differential expansion remains unclear.

The occurrence of small fluid bubbles in clinopyroxene is the first finding of fluids from the transition zone. So far it was not possible to determine whether these "bubbles" contain $\mathrm{OH}, \mathrm{CH}_{4}$ or $\mathrm{CO}$ species.

\section{REFERENCES}

Brenker, F.E., Stachel, T., Harris, J.W., 2002. Exhumation of lower mantle inclusions in diamond - ATEM investigation of retrograde phase transitions, reactions and exsolution - EPSL, 198, 1-9.

Gueguen, Y., 1977. Dislocations in mantle peridotite nodules, Tectonophysics 39, 231-254.

Langenhorst, F., Poirier, J.P., Deutsch, A., Hornemann, U. 2002. Experimental approach to generate shock veins in single crystal olivine by shear melting, MAPS 37, 1541-1553.

Stachel, T., Brey, G.P., Harris, J.W., 2000a. Kankan diamonds (Guinea) I: from the lithosphere down to the transition zone, Contrib Mineral Petrol 140, 1-14.

Stachel, T., Harris, J.W., Brey, G.P., Joswig, W., $2000 \mathrm{~b}$. Kankan diamonds (Guinea) II: lower mantle inclusion parageneses, Mineral Petrol 140, 16-27.

Contact: FE Brenker, Universitaet zu Koeln, Institut fuer Mineralogie und Geochemie, Zülpicher Str. 49 b, 50674

Koeln, Germany, E-mail: brenker@min.uni-koeln.de 